\title{
Iris and periocular adverse reactions to bimatoprost in Japanese patients with glaucoma or ocular hypertension
}

This article was published in the following Dove Press journal:

Clinical Ophthalmology

II January 2012

Number of times this article has been viewed

\author{
Kenji Inoue' \\ Minako Shiokawa' \\ Michitaka Sugahara' \\ Risako Higa' \\ Masato Wakakura' \\ Goji Tomita ${ }^{2}$ \\ 'Inouye Eye Hospital, Tokyo, \\ Japan; ${ }^{2}$ Second Department of \\ Ophthalmology, Toho University \\ School of Medicine, Tokyo, Japan
}

Correspondence: Kenji Inoue Inouye Eye Hospital, 4-3 KandaSurugadai, Chiyoda-ku,

Tokyo I0I-0062, Japan

$\mathrm{Tel}+8 \mid 3329509$ II

Fax +81332950917

Email inoue-k@inouye-eye.or.jp
Purpose: To prospectively investigate adverse reactions to bimatoprost in Japanese patients with glaucoma or ocular hypertension. We also examined patient attitudes to adverse reactions via a questionnaire.

Methods: Fifty-two Japanese patients with glaucoma or ocular hypertension were enrolled. Iridial, eyelid, and eyelash photographs were taken before and at 6 months after bimatoprost treatment. Increase in eyelid pigmentation, iridial pigmentation, eyelash growth and bristle, and vellus hair of the lid was assessed from the photographs. Questionnaires completed by patients provided insight into their subjective judgment of adverse reactions.

Results: Increase in eyelash bristle (53.8\%), iris pigmentation (50.0\%), eyelash growth $(46.2 \%)$, vellus hair of the lid (40.4\%), and eyelid pigmentation (7.7\%) was evident after bimatoprost treatment. The objective and subjective assessments were in agreement in terms of increase in eyelash bristle, eyelash growth, and increase in vellus hair of the lid.

Conclusion: Most patients were conscious of these adverse reactions. Before administering bimatoprost, sufficient explanation of potential adverse reactions should be provided; after initiating treatment, careful observation is required.

Keywords: bimatoprost, adverse reaction, eyelid pigmentation, changes in eyelashes, iris pigmentation

\section{Introduction}

In Japan, bimatoprost (Lumigan ${ }^{\circledR}$, Allergan Inc, Irvine, CA) was approved after latanoprost, travoprost, and tafluprost as a prost-type prostaglandin analog in 2009 . Latanoprost, travoprost, and tafluprost selectively interact with a prostaglandin F (PGF) receptor to reduce intraocular pressure by increasing uveoscleral outflow. Bimatoprost is an endogenous bioactive substance of $\mathrm{PGF}_{2 \alpha}$, an analog with a chemical structure similar to $\mathrm{PGF}_{2 \alpha}$, which selectively interacts with prostaglandin receptors to reduce intraocular pressure. ${ }^{1}$ In a randomized-monocular test, bimatoprost was statistically and clinically superior to latanoprost for treatment of open-angle glaucoma or ocular hypertension in Japanese patients. ${ }^{2}$ Bimatoprost also has a greater hypotensive effect compared to latanoprost in normal-tension glaucoma, ${ }^{3}$ chronic glaucoma or ocular hypertension, ${ }^{4}$ a greater hypotensive effect compared to timolol in chronic glaucoma or ocular hypertension, ${ }^{5}$ and an equivalent hypotensive effect to latanoprost and travoprost in open-angle glaucoma and ocular hypertension. ${ }^{6,7}$

Adverse reactions such as conjunctival injection, changes in eyelashes, eyelid pigmentation, iris pigmentation, and superficial punctate keratitis associated with bimatoprost, latanoprost, travoprost, and tafluprost have been reported. ${ }^{2-13}$ 
However, only a few studies have examined changes in eyelashes, eyelid pigmentation, and iris pigmentation after bimatoprost treatment in Japanese glaucoma patients. ${ }^{2}$

In this study, we objectively and subjectively evaluated the frequency of adverse effects such as eyelash growth and bristle, eyelid pigmentation, increase in vellus hair of the lid, and iris pigmentation when prescribing bimatoprost for 6 months to patients with glaucoma or ocular hypertension.

\section{Subjects and methods Subjects}

Fifty-two Japanese patients (22 male, 30 female) aged 32-81 years (mean, 57.3; standard deviation, 13.1) were enrolled in this study. The types of glaucoma present in the sample included 47 cases of normal-tension glaucoma, four of primary open-angle glaucoma, and one of ocular hypertension. At first, we enrolled 70 patients. But 18 patients discontinued treatment before 6 months due to noncompliance or inability to meet schedule $(n=4)$, hyperemia $(n=6)$, deepening of the upper eyelid sulcus $(n=3)$, and eyelid pigmentation, eyelash bristle, eye pain, headache, and foggy eyesight ( $\mathrm{n}=1$ for each). These 18 patients were excluded from photograph judgment whereas all 52 patients were included in the questionnaire of subjective adverse reaction judgment. The standard types of each adverse reaction are shown in Figure 1.

This study was approved by the Ethics Committee of Inouye Eye Hospital. The subjects were Japanese patients with primary open-angle glaucoma or ocular hypertension that had not been treated before. The patients received treatment with bimatoprost monotherapy at Inouye Eye Hospital from December 2009 to October 2010. All subjects provided written informed consent prior to participation in the study. For statistical analysis, if both eyes were eligible, the right eye was chosen.

Patients were adequately informed about the details of the study and adverse reactions regarding eyelash growth and bristliness, increase in the amount of vellus hair of the lid, eyelid pigmentation, and iris pigmentation that might occur when using bimatoprost. Eye drops were administered once daily in the evening, and facial (eyelid) cleansing was recommended after treatment.

\section{Photography}

We photographed the anterior segment before and after bimatoprost use for 6 months. Eyes of healthy people $(n=9)$

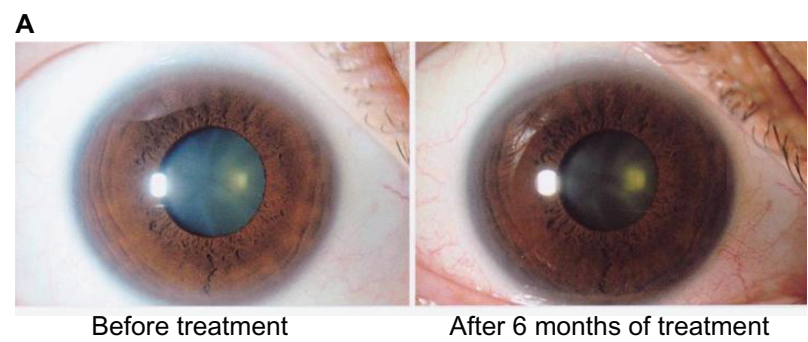

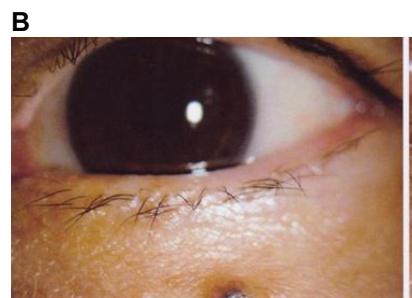

Before treatment

C

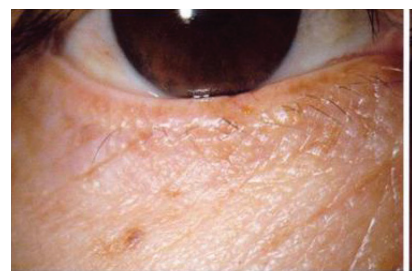

Before treatment

D

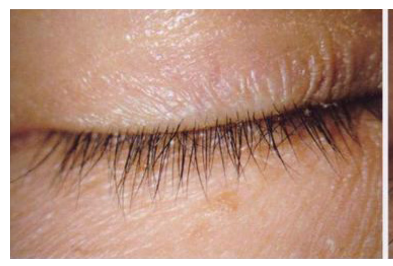

Before treatment

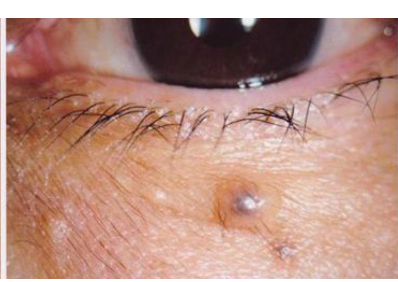

After 6 months of treatment

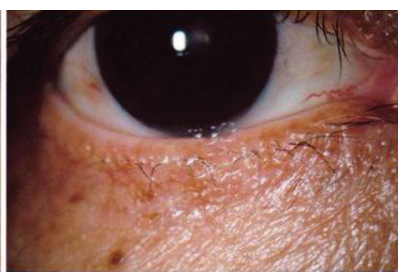

After 6 months of treatment

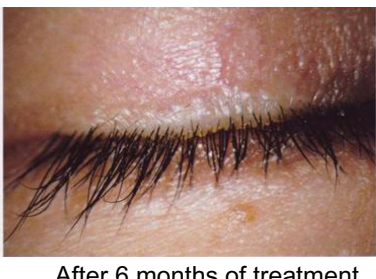

After 6 months of treatment
Figure I Adverse reactions to bimatoprost around the eyes (A) Iris pigmentation, (B) Increase in vellus hair of the lid, (C) Eyelid pigmentation, (D) Eyelash growth and bristliness.

who had no eye disease other than refractive error were also photographed and served as controls.

Biomicroscopy was performed using a slit lamp (RS-1000; Right Mfg Co, Ltd, Miyagi, Japan) and Nikon D200 digital camera (Tokyo, Japan) at a resolution of 10 megapixels. Lighting for the photographs was directed at $30^{\circ}$ from the ipsilateral ear side. The whole iris was photographed with diffuse light (10 times, manual flash mode, amount of light = 3) and the eyelids were photographed in open and closed positions with diffuse light (7.5 times, manual flash mode, amount of light $=1)$. The images were recorded by an electronic filing system (VK-2 Server, Kowa, Nagoya, Japan), and a dye-sublimation thermal transfer printer (CP900D, Mitsubishi, Tokyo, Japan) was used for printing. Photography was performed by four skilled operators. 


\section{Questionnaire survey}

After 6 months of treatment, we conducted a survey using a written questionnaire to evaluate patients' subjective judgment regarding the treatment. The survey consisted of the following questions:

1. Did your eyelashes grow?

2. Did your eyelashes become bristly?

3. Did the vellus (fine, light-colored hair) around your eyelids grow?

4. Did the skin around your eyes become darker?

5. Did the iris become darker?

6. Did you notice any other change(s)?

All questions were required to be answered with either "Yes" or "No".

\section{Appearance of adverse reactions}

Investigator-masked judgment was individually performed by three ophthalmologists who compared pictures obtained before and after treatment with bimatoprost, as well as controls. They judged the existence or nonexistence of five criteria (eyelash growth, eyelash bristle, increase in vellus hair of the eyelid, eyelid pigmentation, and iris pigmentation). The presence of adverse reactions was defined as agreement by at least two of the three ophthalmologists.

\section{Statistics}

The primary safety variable was analyzed by Fisher's exact test or Chi-square test. Independent $t$-tests were used to analyze variables between groups and paired $t$-tests within groups. A $P$ value of 0.05 was considered significant.

\section{Results}

\section{Appearance of adverse reactions}

We compared cases where treatment was discontinued within 6 months of administration (18 cases) to cases where treatment continued for 6 months (52 cases). Mean ages were $63.7 \pm 11.4$ years in the discontinued group and $57.3 \pm 13.1$ years in the continued group, which did not represent a significant difference $(P=0.07)$. Gender in the discontinued group $($ male $=4$, female $=14$ ) and the continued group ( male $=22$, female $=30$ ) was not significantly different $(P=0.22)$. Disease type for the discontinued group (normal tension glaucoma $=14$, primary open-angle glaucoma $=3$, ocular hypertension $=1$ ) and the continued group (normal tension glaucoma $=47$, primary open-angle glaucoma $=4$, ocular hypertension $=1$ ) was not significantly different $(P=0.38)$. Intraocular pressure before administering bimatoprost was $17.5 \pm 3.5 \mathrm{mmHg}$ in the discontinued group and $17.5 \pm 3.1 \mathrm{mmHg}$ in the continued group, which did not represent a significant difference $(P=0.98)$.

Forty-two of 52 patients $(80.8 \%)$ were judged to have had adverse reactions to treatment, such as eyelash growth and bristle, increase in vellus hair of the lid, eyelid pigmentation, or iris pigmentation (Figure 2). Among these patients, $45.2 \%$ were men and $54.8 \%$ women. Their mean age was $59.6 \pm 11.6$ years. There was no statistically significant difference in the incidence of adverse reactions between men and women $(P=0.60$; Fisher's exact test). Patients without adverse reactions (mean age $47.5 \pm 15.1$ years) were significantly younger than those with adverse reactions (mean age $59.9 \pm 11.8$ years $)(P=0.0075$; independent $t$-test $)$. Eyelash growth was seen in 24 cases (46.2\%), eyelash bristle in 28 cases $(53.8 \%)$, increase in vellus hair of the lid in 21 cases (40.4\%), eyelid pigmentation in four cases $(7.7 \%)$, and iris pigmentation in 26 cases $(50.0 \%)$.

\section{Self-assessment questionnaire}

According to patients' self-assessment questionnaires, eyelashes grew longer in 28 cases $(53.8 \%)$, eyelashes became more bristled in 26 cases $(50.0 \%)$, vellus hair of the lid became thicker in 17 cases (32.7\%), and skin around the eyes became darker (eyelid pigmentation) in 23 cases (44.2\%) (Figure 3). There were no differences in the subjective evaluation among these four adverse reactions $(P=0.15$; Chi-square test). Iris pigmentation was reported in five cases $(9.6 \%)$, which was significantly lower than the other four reported adverse reactions $(P<0.0001$; Chi-square test).

\section{Comparison of objective and subjective judgments}

According to the objective judgment, 24 patients had adverse reactions of eyelash growth. But among these individuals,

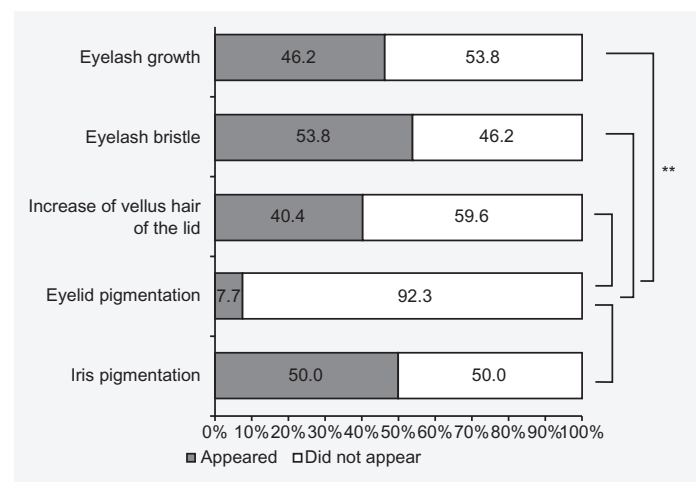

Figure 2 Objective evaluation.

Note: ${ }^{* * P} P 0.000$ I (chi-square test). 


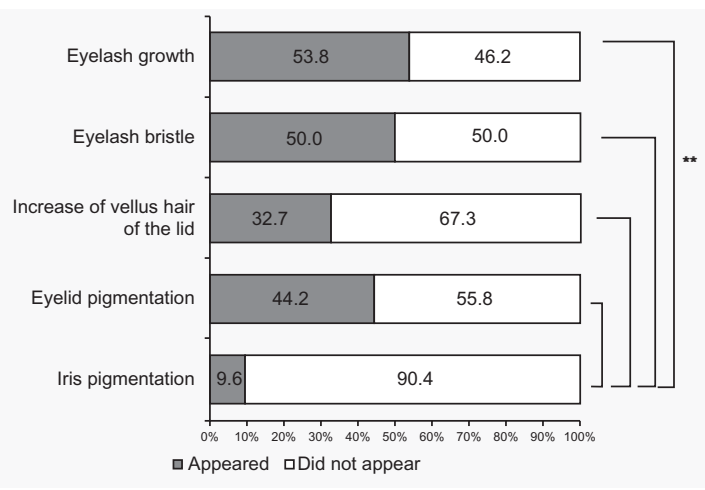

Figure 3 Subjective evaluation.

Note: ${ }^{* *} P<0.000$ I (chi-square test).

only 15 answered "yes" to the subjective judgment (Figure 4). In only 14 of 28 patients $(50.0 \%)$ for eyelash bristle, 10 of $21(47.6 \%)$ for increase in vellus hair, zero of four $(0.0 \%)$ for eyelid pigmentation, and three of $26(11.5 \%)$ for iris pigmentation was there agreement between the subjective assessment and objective judgment. According to objective judgment, 28 patients did not have eyelash growth. But only 15 answered "no" to the subjective judgment (Figure 4). Correspondence between objective and subjective negative judgments was as follows: 12 of $24(50.0 \%)$ for eyelash bristle, 24 of 31 (77.4\%) for increase in vellus hair, 25 of $48(52.1 \%)$ for eyelid pigmentation, and 24 of $26(92.3 \%)$ for iris pigmentation. Positive subjective/objective correspondence (both "yes") for eyelid pigmentation and iris pigmentation was significantly lower than that for eyelash growth, eyelash bristle, and increase in vellus hair of the lid $(P<0.0001$; Chi-square test $)$.

\section{Discussion}

To gain approval for bimatoprost use in Japan, 77 Japanese patients entered a 12 -week clinical trial. ${ }^{2}$ The rate of

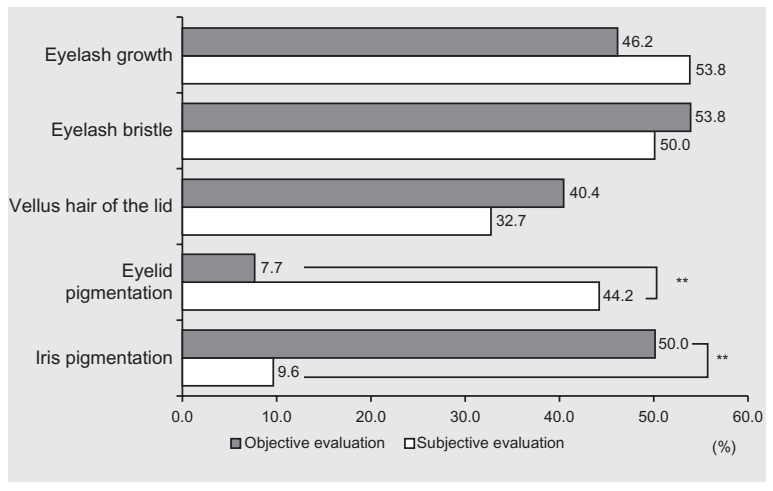

Figure 4 Verification of objective and subjective evaluations. Note: $* * P<0.000$ I (chi-square test). adverse reactions was $66.2 \%$; these reactions included conjunctival injection $(40.3 \%)$, eyelash growth $(31.2 \%)$, eyelid pigmentation (10.4\%), pruritus (7.8\%), dysesthesia of the eye (5.2\%), and conjunctival chemosis (5.2\%). The incidence of these adverse reactions was higher than that reported for latanoprost. ${ }^{2}$

In this study, we found that adverse reactions around the eyes such as eyelash growth and bristle, increase in vellus hair of the lid, eyelid pigmentation, and iris pigmentation appeared in $80.8 \%$ of patients. However in this study, 18 cases discontinued administration of bimatoprost within 6 months. One case each of eyelid pigmentation and eyelash bristle was included. Moreover, in cases where patients discontinued treatment, except for adverse reactions, there are possibilities of appearances of adverse reactions around the eyes that could not be evaluated in this study. This study is an evaluation of administering bimatoprost for 6 months. Therefore, there is a possibility that it underevaluated the actual appearance of adverse reactions. In this present study, extraneous factors between patients who discontinued administration before 6 months and cases where treatment continued for 6 months were compared. There was no significant difference between the two groups. Therefore, a prediction of the cases where treatment is able to continue is difficult to conceive. Moreover, in a comparison between cases where adverse reactions appeared and cases where adverse reactions did not appear, cases where adverse reactions did not appear were significantly younger. This may be because the administering techniques of elderly people are not as good: they may administer too many drops at once, and there are possibilities that they are dropping eye drops onto their eyelids. Young people's adherence to self-administration of the treatment may be poor due to forgetfulness.

In previous studies, eyelash growth was reported in $25.6 \%$ of subjects in a 3 -month trial, ${ }^{5} 2.9 \%^{6}$ and $31.2 \%{ }^{2}$ in 12 -week trials, $48.1 \%$ in a 24 -week trial, ${ }^{6} 10.5 \%$ in a 6 -month trial, ${ }^{4}$ and $42.8 \%$ in a 180 -day trial. ${ }^{8}$ Although the administration periods and evaluation methods differed, the incidence of eyelash growth (46.2\%) and eyelash bristle (53.8\%) in this study was almost equivalent to that in other studies. The incidence of increased eyelid pigmentation was reported as $2.9 \%{ }^{6}$ and $10.4 \%^{2}$ in 12 -week trials, $25.9 \%^{7}$ in a 24 -week trial, $17.8 \%{ }^{8}$ in a 180 -day trial, and $5.8 \%{ }^{9}$ in a 12 -month trial. Although the administration periods and evaluation methods differed in each of these studies, the incidence of increased eyelid pigmentation (7.9\%) in the present study was mostly comparable with these results. Iris pigmentation in 3-month trials was reported as $0 \%{ }^{3}$ and $0.4 \%,{ }^{5}$ in a 6 -month trial, $0.8 \%,{ }^{4}$ 
and in a 12 -week trial, $<5 \% .{ }^{2}$ In this study we evaluated iris pigmentation objectively as $50.0 \%$, which might be more frequent than that in the previous studies. ${ }^{2-5}$ On the other hand, iris pigmentation induced by latanoprost treatment evaluated objectively has been reported as $16.3 \%, 34.2 \%$, $49.2 \%, 58.2 \%$, and $58.2 \%$ at $6,9,9,12$, and 15 months after the start of latanoprost treatment. ${ }^{10}$ Frequency rates rose as progression occurred. In this study, we evaluated the adverse reactions of bimatoprost at only 6 months after treatment. A longer-term safety examination will be needed.

In previous evaluations, $0.0 \%,{ }^{7} 0.9 \%,{ }^{5} 1.5 \%,{ }^{6} 3.3 \%,{ }^{3}$ $4.2 \%,{ }^{2} 4.5 \%,{ }^{4}$ and $9.7 \%{ }^{8}$ of patients discontinued bimatoprost because of adverse reactions. Reasons for discontinuing treatment included conjunctival hyperemia, ocular burning sensation, blurry visual acuity, photophobia, ${ }^{3}$ eyelid pigmentation, ${ }^{2}$ instability dizziness, ${ }^{2}$ eyelid erythema and conjunctival injection, ${ }^{2}$ ocular hyperemia,${ }^{6}$ conjunctival hyperemia, ${ }^{4,5}$ allergic skin reaction, ${ }^{5}$ blepharoptosis, ${ }^{5}$ eye pruritus, ${ }^{4}$ and ocular allergy. ${ }^{8}$ In this study, 14 patients (20\%) discontinued bimatoprost treatment because of adverse reactions. Japanese patients might have a greater proclivity for adverse reactions to bimatoprost treatment. However, incidence of adverse reactions such as hyperemia, eyelid pigmentation, eyelash bristle, eye aching, headache, and foggy eyesight was not significantly different from previously reported incidences in other populations. ${ }^{2-7}$

A control group was not set up in this study. We have investigated the frequency of adverse reactions around the eyes caused by other prostaglandin analogs such as latanoprost, ${ }^{11}$ travoprost, ${ }^{12}$ and tafluprost ${ }^{13}$ in our hospital using the same methods as this study (Figure 5). We took pictures before administration and after administration of prostaglandin analogs. There have been no reports performed in the same way as our reports. ${ }^{11-13}$ Therefore, we compared our results to those reports.

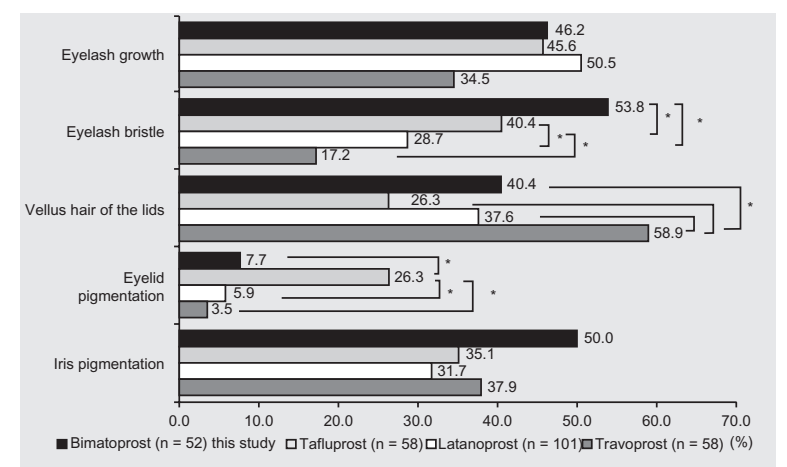

Figure 5 Comparison of adverse reactions among other prostaglandin analogs. ${ }^{11-13}$ Note: $* P<0.05$
Inoue et al enrolled 101 patients for treatment with latanoprost for 6 months. ${ }^{11}$ Eyelash growth appeared in $50.5 \%$, eyelash bristle in $28.7 \%$, increase in vellus hair of the lid in $37.6 \%$, eyelid pigmentation in $5.9 \%$, and iris pigmentation in $31.7 \%$ of patients. Shiokawa et al treated 58 patients with travoprost for 6 months. ${ }^{12}$ Eyelash growth appeared in $34.5 \%$, eyelash bristle in $17.2 \%$, increase in vellus hair of the lid in $58.6 \%$, eyelid pigmentation in $3.5 \%$, and iris pigmentation in $37.9 \%$ of patients. Masumoto et al treated 58 patients with tafluprost for 6 months. ${ }^{13}$ Eyelash growth appeared in $46.6 \%$, eyelash bristle in $41.4 \%$, increase of vellus hair in the lid in $27.6 \%$, eyelid pigmentation in $25.9 \%$, and iris pigmentation in $34.5 \%$ of patients. Eyelash bristle under treatment with tafluprost and bimatoprost, increase in vellus hair of the lid under travoprost treatment, and eyelid pigmentation under tafluprost treatment were more frequently noted than with treatment using other prostaglandin analogs $(P<0.01$; Chi-square test). The reasons underlying these disparities are unknown.

To understand patients' acceptance of adverse events, a self-assessment questionnaire was employed. Even though the results of the comparison between objective and subjective assessments corresponded in the range of $48.1 \%-65.4 \%$, the differences in results between objective and subjective assessments were markedly different for eyelid and iris pigmentation. This may be a result of informing the patients about possible eyelid pigmentation before starting the eye drops, thereby increasing patient consciousness of this potential reaction. To identify iris pigmentation, careful observation is required while standing in front of a mirror. Even if iris pigmentation occurs, it does not result in any visual or esthetical detriment. Therefore, it is often not noted. Two patients discontinued treatment due to eyelid pigmentation and eyelash bristle but we could not evaluate their subjective assessments. Sufficient explanation of adverse reactions is necessary prior to treatment. This may affect the number of patients who continue with treatment.

We observed three cases of discontinuation of treatment due to deepening of the upper eyelid sulcus. Because few studies have described this adverse reaction, its objective and subjective assessments were not examined in this study. However, recent studies have reported deepening of the upper eyelid sulcus following treatment with bimatoprost, travoprost, and latanoprost. ${ }^{14-20}$ In the future, careful observation of deepening of the upper eyelid is recommended.

In conclusion, eyelash bristle, iris pigmentation, eyelash growth, increase in vellus hair of the lid, and eyelid pigmentation were noted, in order of frequency, when prospectively 
investigating adverse reactions to bimatoprost. Most patients were conscious of these adverse reactions. Sufficient explanation and careful observation of potential adverse reactions are necessary when prescribing bimatoprost.

\section{Disclosure}

The authors declare no conflicts of interest in relation to this paper.

\section{References}

1. Liang Y, Woodward DF, Guzman VM, et al. Identification and pharmacological characterization of the prostaglandin FP receptor and FP receptor variant complexes. Br J Pharmacol. 2008;154:1079-1093.

2. Kitazawa Y, Komemushi S. Single-masked, randomized, parallel-group comparison of bimatoprost ophthalmic solution and latanoprost ophthalmic solution in patients with primary open-angle glaucoma or ocular hypertension [in Japanese]. Atarashii Ganka. 2010;27:401-410.

3. Dirks MS, Noecker RJ, Earl M, Roh S, Silverstein SM, Williams RD. A 3-month clinical trial comparing the IOP-lowering efficacy of bimatoprost and latanoprost in patients with normal-tension glaucoma. $A d v$ Ther. 2006;23:385-394.

4. Noecker RS, Dirks MS, Choplin NT, Bernstein P, Batoosingh AL, Whitcup SM; Bimatoprost/latanoprost study group. A six-month randomized clinical trial comparing the intraocular pressure-lowering efficacy of bimatoprost and latanoprost in patients with ocular hypertension or glaucoma. Am J Ophthalmol. 2003;135:55-63.

5. Brandt JD, VanDenburgh AM, Chen K, Whitcup SM; Bimatoprost study group 1. Comparison of once-or twice-daily bimatoprost with twice-daily timolol in patients with elevated IOP. Ophthalmology. 2001;108(6):1023-1031.

6. Parrish RK, Palmberg P, Sheu W-P; XLT study group. A comparison of latanoprost, bimatoprost, and travoprost in patients with elevated intraocular pressure: a 12-week, randomized, masked-evaluator multicenter study. Am J Ophthalmol. 2003;135:688-703.

7. Birt CM, Buys YM, Ahmed IIK, Trope GE; the Toronto area glaucoma society. Prostaglandin efficacy and safety study undertaken by race (the pressure study). J Glaucoma. 2010;19:460-467.
8. Manni G, Centofanti M, Parravano M, Oddone F, Bucci MG. A 6-month randomized clinical trial of bimatoprost $0.03 \%$ versus the association of timolol $0.5 \%$ and latanoprost $0.005 \%$ in glaucomatous patients. Graefes Arch Clin Exp Ophthalmol. 2004;242:767-770.

9. Sharpe ED, Reynolds AC, Skuta GL, Jenkins JN, Stewart WC. The clinical impact and incidence of periocular pigmentation associated with either latanoprost or bimatoprost therapy. Curr Eye Res. 2007;32:1037-1043.

10. Latanoprost-induced iris pigmentation study group. Incidence of a latanoprost-induced increase in iris pigmentation in Japanese eyes. Jpn J Ophthalmol. 2006;50:96-99.

11. Inoue K, Wakakura M, Inoue J, Matsuo H, Hara T, Tomita G. Adverse reaction after use of latanoprost in Japanese glaucoma patients [in Japanese]. Nippon Ganka Gakkai Zasshi. 2006;110:581-587.

12. Shiokawa M, Inoue K, Higa R, et al. Adverse reaction after use of benzalkonium chloride-free travoprost $0.004 \%$ in Japanese glaucoma or ocular hypertension patients [in Japanese]. Atarashii Ganka. 2010;27:1429-1434.

13. Masumoto M, Inoue K, Shiokawa M, et al. Adverse reaction after use of Tafluprost in Japanese glaucoma or ocular hypertension patients [in Japanese]. Rinsho Ganka. 2011;65:1089-1094.

14. Yam JC, Yuen NS, Chan CW. Bilateral deepening of upper lid sulcus from topical bimatoprost therapy. J Ocul Pharmacol Ther. 2009;25:471-472.

15. Filippopoulos T, Paula JS, Torun N, Hatton MP, Pasquale LR, Grosskreutz CL. Periorbital changes associate with topical bimatoprost. Ophthal Plast Reconstr Surg. 2008;24:302-307.

16. Peplinski LS, Smith KA. Deepening of lid sulcus from topical bimatoprost therapy. Optom Vis Sci. 2004;81:574-577.

17. Yang HK, Park KH, Kim TW, Kim DM. Deepening of eyelid superior sulcus during topical travoprost treatment. Jpn J Ophthalmol. 2009;53:176-179.

18. Aydin S, LŞıklıgil L, TekȘen YK. Recovery of orbital fat pad prolapsus and deepening of the lid sulcus from topical bimatoprost therapy: 2 case reports and review of the literature. Cutan Ocul Toxicol. 2010;29:212-216.

19. Jayaprakasam A, Ghazi-Nouri S. Periorbital fat atrophy- an unfamililiar side effect of prostaglandin analogues. Orbit. 2010;29:357-359.

20. Park J, Cho HK, Moon JI. Changes to upper eyelid orbital fat from use of topical bimatoprost, travoprost, and latanoprost. Jpn J Ophthalmol. 2011;55:22-27.
Clinical Ophthalmology

\section{Publish your work in this journal}

Clinical Ophthalmology is an international, peer-reviewed journal covering all subspecialties within ophthalmology. Key topics include: Optometry; Visual science; Pharmacology and drug therapy in eye diseases; Basic Sciences; Primary and Secondary eye care; Patient Safety and Quality of Care Improvements. This journal is indexed on Submit your manuscript here: http://www.dovepress.com/clinical-ophthalmology-journal

\section{Dovepress}

PubMed Central and CAS, and is the official journal of The Society of Clinical Ophthalmology (SCO). The manuscript management system is completely online and includes a very quick and fair peer-review system, which is all easy to use. Visit http://www.dovepress.com/ testimonials.php to read real quotes from published authors. 